\title{
Determination of Licochalcone A in Rat Plasma by UPLC-MS/MS and Its Pharmacokinetics
}

\author{
Qinghua Weng ${ }^{1}$, Lianguo Chen ${ }^{1}$, Luxin $\mathrm{Ye}^{2}$, Xiaojie $\mathrm{Lu}^{2}$, Zheng $\mathrm{Yu}^{2}$, Congcong $\mathrm{Wen}^{2}$, \\ Yichuan Chen ${ }^{1^{*}}$ and Gang Huang ${ }^{3,4^{*}}$ \\ ${ }^{1}$ The Third Clinical Institute Affiliated to Wenzhou Medical University \& Wenzhou People's Hospital, Wenzhou 325000, China \\ ${ }^{2}$ Laboratory Animal Centre, Wenzhou Medical University, Wenzhou, 325035, China \\ ${ }^{3}$ Department of Traditional Chinese Medicine, The Sixth Affiliated Hospital of Wenzhou Medical University, \\ The People's Hospital of Lishui, Lishui 323000, China \\ ${ }^{4}$ Institute of Integrated Traditional Chinese and Western Medicine of Lishui, Lishui 323000, China
}

Received: 19 May 2018; accepted: 05 July 2018

\begin{abstract}
The aim of this study was to establish a rapid, sensitive, and selective ultra-performance liquid chromatographytandem mass spectrometry (UPLC-MS/MS) method to quantify the concentrations of licochalcone A and applicate the technique to its pharmacokinetic study. Analytes were separated on an UPLC ethylene bridged hybrid (BEH) C18 column $(2.1 \mathrm{~mm} \times 50 \mathrm{~mm}, 1.7 \mu \mathrm{m})$. The mobile phase was consisted of acetontrile and $0.1 \%$ formic acid with a flow rate of $0.4 \mathrm{~mL} / \mathrm{min}$ in a gradient elution mode. Multiple-reaction monitoring (MRM) was carried out in a negative mode for licochalcone A $(\mathrm{m} / \mathrm{z} 337.2 \rightarrow 119.7)$ and the internal standard (IS) $(\mathrm{m} / \mathrm{z} 609.0 \rightarrow 300.9)$. The linearity of licochalcone A was great from 0.53 to $530 \mathrm{ng} / \mathrm{mL}$. The lower limit of quantification and the lower limit of detection were $0.53 \mathrm{ng} / \mathrm{mL}$ and $0.26 \mathrm{ng} / \mathrm{mL}$, respectively. The intra-day precision was less than $14 \%$, and the inter-day precision was no more than $11 \%$. The accuracy was from $91.5 \%$ to $113.9 \%$, the recovery was over $90.5 \%$, and the matrix effect was between $84.5 \%$ and $89.7 \%$. The results of stability were in an acceptable range. The bioavailability was only $3.3 \%$, exhibiting poor absorption. The developed method was successfully applicable for determining the concentrations of licochalcone A and its pharmacokinetic study.
\end{abstract}

Keywords: UPLC-MS/MS, licochalcone A, pharmacokinetics, bioavailability

\section{Introduction}

Licorice, originates from the roots and rhizomes of Glycyrrhiza uralensis, is one of the most commonly and widely consumed herbs in the world. Licorice was listed for invigorating spleen, detoxification, removing phlegm, and the treatment of asthma, pain, fever cough, and stomach ulcer in the Chinese Pharmacopoeia [1]. Previous investigations have shown that glycyrrhizin and its derivatives in licorice were the main active components responsible for the hepatic protective and anti-ulcer effects of licorice [2]. Licochalcone A, a major natural chalcone derived from licorice, was also reported to have a variety of bioactivities, such as antioxidant, anti-inflammatory, antispasmodic activity, immunomodulatory effects, and antibacterial activities [3-6]. In recent years, licochalcone A have caught more attention of researchers due to its potent anti-cancer activity to different kinds of cancers [7], including cervical cancer [8], lung cancer [9], breast cancer [10], bladder cancer [11], gastric cancer [12], and so on.

In order to further understand the regulation of absorption, distribution, and metabolism, it was important to perform a pharmacokinetic study for clinical practice. Therefore, it was necessary to develop a quantitative method to detect the concentrations of licochalcone A in rat plasma for pharmacokinetic study. Until now, only a few researches for detecting the concentrations of licochalcone A were reported. Previous study showed that the contents of licochalcone A were investigated in ethanolic extracts of plant specimens by a capillary-zone electrophoresis (CZE) method [13] and in biological fluids by a high-performance liquid chromatography (HPLC) method [14], respectively. In addition,

* Authors for correspondence: chuancyc10@126.com (Y.C.); hyg91264@qq. com (G.H.)
Huang et al. investigated the hepatic metabolism of licochalcone A using liquid chromatography-mass spectrometry (LC-MS) method in human liver microsomes [15]. However, to date, the pharmacokinetics of licochalcone A has not been reported.

Compared with capillary-zone electrophoresis, HPLC, and LC-MS, an ultra-performance liquid chromatography-tandem mass spectrometry (UPLC-MS/MS) method was more sensitive, high throughput, and time saving [16-20]. In this study, licochalcone A was quantified using a newly developed and validated UPLC-MS/MS method to evaluate its pharmacokinetics in SD rat plasma after intravenous and gavage administration.

\section{Materials and Methods}

Experimental Materials. Licochalcone A (purity: $>98 \%$, presented at Figure 1A) and neohesperidin (purity: $>98 \%$, presented at Figure 1B) were bought from Chengdu Mansite BioTechnology Co., Ltd. (Chengdu, China). Chromatographic methanol and acetonitrile (ACN) were purchased from Merck (Darmstadt, Germany). Chromatographic formic acid was got from Tedia (Ohio, USA). A Milli-Q system (Bedford, MA, USA) used for providing ultrapure water was needed. Sprague Dawley (SD) rats (male, weight 200-220 g) were provided by Animal Experimental Central of Wenzhou Medical University.

Experimental Device. The UPLC-MS/MS system was consisted of ACQUITY I-Class UPLC and XEVO TQ-S micro triple quadrupole mass spectrometer (Waters Corp, Milford, MA, USA) with an electrospray ionization (ESI) source. The outputsignal monitoring and processing were performed by Masslynx 4.1 software (Waters Corp.).

Desolvation gas and cone gas were filled with high purity nitrogen with a flow rate of $800 \mathrm{~L} / \mathrm{h}$ and $50 \mathrm{~L} / \mathrm{h}$, respectively.

This is an open-access article distributed under the terms of the Creative Commons Attribution-NonCommercial 4.0 International License (https://creativecommons.org/licenses/by-nc/4.0/), which permits unrestricted use, distribution, and reproduction in any medium for non-commercial purposes, provided the original author and source are credited, a link to the CC License is provided, and changes - if any - are indicated. 
<smiles>C=CC(C)(C)c1cc(/C=C/C(=O)c2ccc(O)cc2)c(OC)cc1O</smiles>

(A)<smiles>COc1ccc([C@H]2CC(=O)c3c(O)cc(O[C@@H]4O[C@H](CO)[C@@H](O)[C@H](O)[C@H]4O[C@@H]4O[C@H](C)[C@@H](O)[C@H](O)[C@H]4O)cc3O2)cc1O</smiles>

(B)

Figure 1. The chemical structure of licochalcone A (A) and neohesperidin (B)

The parameters of detector in the negative mode (ESI-) were presented as follows: capillary voltage was set to $2.2 \mathrm{kV}$, the temperature of the ESI source, and desolvent were separately $150{ }^{\circ} \mathrm{C}$ and $400{ }^{\circ} \mathrm{C}$. Multiple reaction monitoring mode was applied in a negative mode for licochalcone A ions at $m / z 337.2 \rightarrow 119.7$ (the collision voltage was $15 \mathrm{~V}$, and the cone voltage was $32 \mathrm{~V}$ ) and IS ions at $\mathrm{m} / \mathrm{z} 609.0 \rightarrow 300.9$ (the collision voltage was $26 \mathrm{~V}$, and the cone voltage was $35 \mathrm{~V}$ ).

The UPLC analysis was performed on an UPLC BEH C18 column $(2.1 \mathrm{~mm} \times 50 \mathrm{~mm}, 1.7 \mu \mathrm{m})$. The mobile phase contained acetonitrile $(\mathrm{ACN})$ and $0.1 \%$ formic acid with a flow rate of $0.4 \mathrm{~mL} / \mathrm{min}$. The temperature of column was set at $40{ }^{\circ} \mathrm{C}$. An effective chromatographic separation was achieved in a gradient elution mode with a total time of $4 \mathrm{~min}$. The chromatographic separation was set as follows: ACN kept at $10 \%$ for $0.2 \mathrm{~min}$, then changed linearly to $75 \%$ in 1.3 min and was maintained at $75 \%$ for $0.5 \mathrm{~min}$, subsequently decreased to $10 \%$ in $0.5 \mathrm{~min}$, and finally equilibrated again with $10 \%$ for $1.5 \mathrm{~min}$.

Preparation of Standard Solutions. The stock solutions of licochalcone A and neohesperidin were made up of methanol at a final concentration of $1.0 \mathrm{mg} / \mathrm{mL}$ and $0.1 \mathrm{mg} / \mathrm{mL}$, respectively. A batch of standard working solutions of licochalcone A at several concentration levels was obtained from stock solutions diluted with ACN. The standard working solution of the internal standard (IS) was diluted with ACN to get a final concentration of $100 \mathrm{ng} / \mathrm{mL}$. All the solutions were stored at $4{ }^{\circ} \mathrm{C}$.

Calibration Standards (CS) and Quality Control (QC) Samples. The CS samples of licochalcone A were prepared by mixing blank rat plasma with appropriate corresponding working solutions. The final concentrations of calibration standard were from 0.53 to $530 \mathrm{ng} / \mathrm{mL}(0.53,2.65,5.3,10.6,26.5,53,106$, 265, and $530 \mathrm{ng} / \mathrm{mL}$ ). The QC samples were prepared in the same way to three different concentrations (low-, mid-, and highlevel) at 1.06, 95.4, and $424 \mathrm{ng} / \mathrm{mL}$ for evaluating accuracy, precision, and stability. All the solutions were stored at $4{ }^{\circ} \mathrm{C}$ until processed.

Preparation of Plasma Samples. Licochalcone A and IS were simultaneously extracted from the plasma specimens $(50 \mu \mathrm{L})$ in $1.5 \mathrm{~mL}$ test tubes using direct precipitation by adding $150 \mu \mathrm{L}$ ACN (containing $100 \mathrm{ng} / \mathrm{mL}$ IS). After a full mix for $1 \mathrm{~min}$, these tubes were centrifugated with a high speed of $13,000 \mathrm{rpm}$ at $4{ }^{\circ} \mathrm{C}$ for $10 \mathrm{~min}$. Then, $100 \mu \mathrm{L}$ supernate was carefully removed into a new Micro-insert (clear glass, cone-shaped with plastic stent). Finally, $2 \mu \mathrm{L}$ of aliquot liquid was injected into the UPLC-MS/MS system for analysis.

Validation of Methods. Selectivity was estimated by detecting blank plasma samples, blank plasma samples adding licochalcone A and IS and plasma samples from a rat after dosing. Plasma specimens were prepared using the preparation procedure described above.

The calibration curves were measured by analyzing the peakarea ratios of licochalcone A against the corresponding IS versus the nominal concentration $(x)$ of licochalcone A using a leastsquares linear regression method. The linearity was investigated at 9 levels covering the concentration ranging from 0.53 to $530 \mathrm{ng} / \mathrm{mL}$. The linearity could be accepted when the correlation coefficient $\left(r^{2}\right)$ was over 0.99 .

According to the guidelines of the Food and Drug Administration (FDA) [21], the lower limit of detection (LLOD) of the targets must achieve requirements that ratios of signal to noise $(S / N)$ were over $3: 1$. The lower limit of quantification (LLOQ) of targets was calculated as the lowest concentration of quantitive analysis when $S / N$ was at least 10 .

Precision was evaluated by determining three different concentrations of QCs $(1.06,95.4$, and $424 \mathrm{ng} / \mathrm{mL} ; n=6)$ for three consecutive days. Inter-day and intra-day precisions were calculated as RSD value (less than $15 \%$ ) for validation.

The peak area ratios of the three concentrations of QCs (1.06, 95.4, and $424 \mathrm{ng} / \mathrm{mL}$ ), which were added before extraction (IS were added after) against those of the corresponding standard samples obtained by adding licochalcone A and IS after the extraction step, were used to evaluate the recovery $(n=6)$.

The matrix effect was calculated by comparison of the peak areas of licochalcone $\mathrm{A}$ in the extracted blank plasma samples at the three concentrations $(1.06,95.4$, and $424 \mathrm{ng} / \mathrm{mL})$ with those of the corresponding standard solutions dissolved with $\mathrm{ACN}$ and $0.1 \%$ formic acid $(1: 1, v / v)$ at equivalent concentrations $(n=6)$.

The stability of licochalcone A in rat plasma was evaluated by comparing the areas of the QCs at three concentrations $(1.06,95.4$, and $424 \mathrm{ng} / \mathrm{mL})$ in the plasma samples $(n=3)$. Stability experiments were carried out in four different storage conditions, including storage at room temperature for 6 hours, storage at $-70{ }^{\circ} \mathrm{C}$ for a month, and freeze-thaw conditions (from $-70{ }^{\circ} \mathrm{C}$ to room temperature, 3 cycles).

Pharmacokinetic Study. Before administration, SD rats were allowed to eat and drink freely and were kept at room temperature with $12 \mathrm{~h}$ on and $12 \mathrm{~h}$ off light cycle for seven days. Licochalcone A was dissolved in 2\% DMSO solution for dosing and freshly prepared before the experiment. All rats $(n=12)$ were divided into two groups (group A and group B, $n=6$ for each group). Group $A$ received licochalcone A intravenously $(5 \mathrm{mg} / \mathrm{kg})$, while group $B$ received this compound orally (15 mg/kg licochalcone A). Over $200 \mu \mathrm{L}$ of the blood specimens were collected from casual vein before dosing and at $0.083,0.25,0.5,1,2,3,4,6$, and $12 \mathrm{~h}$ after administration and transformed into $1.5 \mathrm{~mL}$ Eppendorf (EP) tubes contained heparin. A $50 \mu \mathrm{L}$ of plasma was acquired after centrifugation at $3000 \mathrm{rpm}$ for $10 \mathrm{~min}$ and stored at $-20{ }^{\circ} \mathrm{C}$. DSA software (Version 2.0, China Pharmaceutical University, China) was used for calculating pharmacokinetic parameters. Bioavailability was calculated as Absolute bioavailability $=100 \% \times$ AUCpo $\cdot$ Div/(AUCiv $\cdot$ Dpo), where AUCiv and AUCpo are the AUC of the drug from 0 to $\infty$ after intravenous and oral administration. Div and Dpo are the single dosage of licochalcone A for intravenous and oral administrations, respectively. 


\section{Results and Discussion}

Optimization of Methods. To optimize the MS conditions, the choice of positive and negative modes of the ESI source played an important role in the methodology [22, 23]. Licochalcone A, a kind of flavonoids, was an acidic compound because it contains phenolic hydroxyl groups. Therefore, the negative mode was more suitable for the determination of licochalcone A theoretically. Ultimately, we chose the negative ESI mode for the detection because of the more strong and stable responses of the analytes, as compared to the positive ion mode.

Endogenous compounds in plasma might interfere the determination of analytes; therefore, a suitable mobile phase condition was necessary to isolate these compounds from analytes at same retention times and obtain a more symmetrical peak shape $[24,25]$. Four different combinations of mobile phase were investigated in this study, including ACN and $0.1 \%$ formic acid, ACN and $10 \mathrm{mmol} / \mathrm{L}$ ammonium acetate solutions $(0.1 \%$ formic acid included), methanol and $0.1 \%$ formic acid, and methanol and $10 \mathrm{mmol} / \mathrm{L}$ ammonium acetate solutions $(0.1 \%$ formic acid included). As a result, ACN and $0.1 \%$ formic acid was used as the mobile phase in gradient elution mode for less analysis time, sharper chromatographic peak shape, and the most satisfied resolution.

The plasma is a kind of complex biological specimen with a lot of endogenous substances and proteins, and different extraction methods would directly affect the results of quantification [26-31]. Thus, an effective and simple sample preparation is needed to get rid of these substances before UPLC-MS/MS analysis and obtain a superior bioanalysis method [32-37]. Liquidliquid extraction and direct protein precipitation were two commonly used sample preparation methods. In this current research, analytes were extracted by liquid-liquid extraction with ethyl acetate, chloroform, and ether and by direct protein precipitation with methanol, ACN, the mixture of ACN, and methanol $(1: 1, v / v)$. Even though liquid-liquid extraction had a better extraction and matrix effect, protein precipitation by $\mathrm{ACN}$ was the best choice in this study for its relatively good recovery and an acceptable matrix effect. As a result, liquid-liquid extraction (LLE) has the advantage of a higher extraction rate and lower limit of quantification compared with the protein precipitation, but directly precipitation with ACN was the best choice in this study for saving more time and its relatively good recovery and an acceptable matrix effect.

\section{Validation of Methods}

Selectivity. Figure 2 presented the typical UPLC-MS/MS mass spectrum of the blank plasma extract spiked with

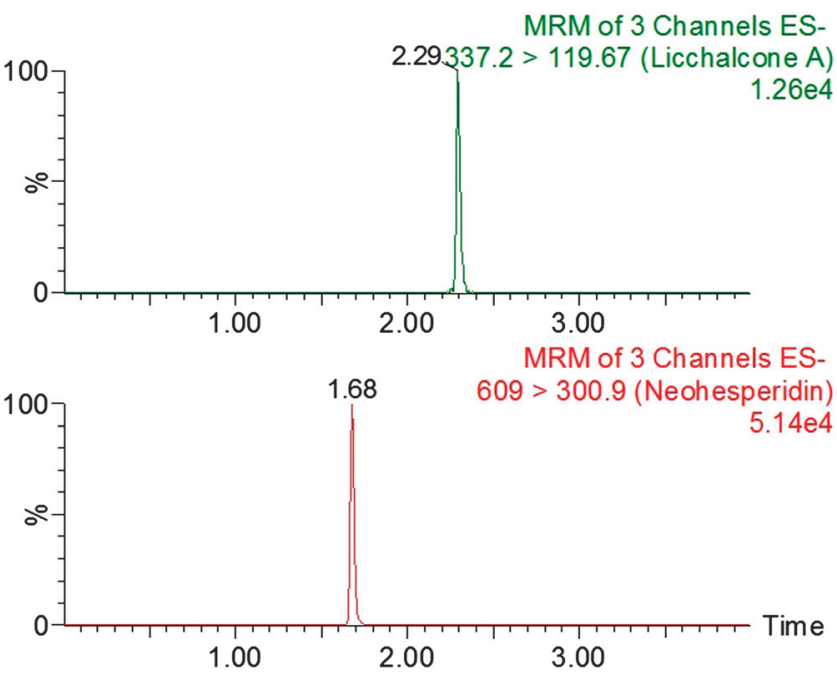

Figure 2. The MS/MS chromatograms of licochalcone A and neohesperidin (IS): a blank extract with medium chain triglycerides (MCT) and IS licochalcone A and IS. There was no interference peak observed at the retention time of licochalcone A or IS, showing a great selectivity.

Calibration Curve. The regression equation of calibration curve was $y=0.0045 x+0.0061(r=0.9984)$ for licochalcone A. Among them, $y$ is the peak area ratio of licochalcone A against IS, $x$ is the concentration of licochalcone A. The linearity of licochalcone $\mathrm{A}$ is great in the calibration curves over the concentration range 0.53 to $530 \mathrm{ng} / \mathrm{mL}$ in rat plasma. The LLOQ was $0.53 \mathrm{ng} / \mathrm{mL}$, and the LLOD was $0.26 \mathrm{ng} / \mathrm{mL}$.

Precision, Accuracy, Recovery, and Matrix Effect. Table 1 presented the precision, accuracy, recovery, and matrix effect of licochalcone A. Intra-day precision assessed using the relative standard deviation (RSD) was less than $14 \%$, and the interday precision (RSD) was no more than $11 \%$. The accuracy ranged from $91.5 \%$ to $113.9 \%$ at each QC level. All of the recoveries were over $90.5 \%$, and the matrix effects were between $84.5 \%$ and $89.7 \%$. These data suggest that the precision, accuracy, recovery, and matrix effect of licochalcone A were in the acceptable range according the guidelines of the FDA, and the established UPLC-MS/MS method met the pharmacokinetic study.

Stability. The results showed that licochalcone A stored at room temperature for $6 \mathrm{~h},-70{ }^{\circ} \mathrm{C}$ for a month, or after three freeze-thaw cycles was stable (RSDs $\leq 15 \%$ in all stability tests), which indicated a reliable stability behavior of licochalcone A under the different storage conditions.

Pharmacokinetic Study. No adverse reactions were observed in the two groups throughout the experimental process. The validated method was successfully applied to intravenous and oral administration study of licochalcone A in rats. Pharmacokinetics is a discipline that quantitatively investigates the absorption, distribution, and excretion of drug in vivo. The pharmacokinetics of licochalcone A was reported for the first time.

The mean blood concentration-time curves of licochalcone A are shown in Figures 3 and 4, respectively. The main pharmacokinetic parameters after dosing based on non-compartment mode were shown in Table 2. The $\mathrm{AUC}_{(0-t)}$ was $2479.9 \pm 326.6 \mathrm{ng} /$ $\mathrm{mL}^{*} \mathrm{~h}$ and $243.3 \pm 44.4$ for intravenous and oral administration. The bioavailability of licochalcone A was only $3.3 \%$. The low

Table 1. Accuracy, precision, matrix effect, and recovery of licochalcone A in $\mathrm{SD}$ rat plasma

\begin{tabular}{lrrrrrrr}
\hline $\begin{array}{l}\text { Concentration } \\
(\mathrm{ng} / \mathrm{mL})\end{array}$ & \multicolumn{2}{c}{ Accuracy (\%) } & & Precision $(\mathrm{RSD} \%)$ & $\begin{array}{c}\text { Matrix } \\
\text { effect }\end{array}$ & $\begin{array}{c}\text { Recovery } \\
(\%)\end{array}$ \\
\cline { 2 - 3 } & Intra-day & Inter-day & & Intra-day & Inter-day & & \\
\hline 0.53 & 112.9 & 113.9 & & 13.0 & 10.7 & 84.5 & 95.7 \\
1.06 & 91.5 & 96.2 & & 4.4 & 2.7 & 86.8 & 92.6 \\
95.4 & 100.9 & 93.3 & & 7.4 & 9.4 & 89.7 & 90.5 \\
424 & 97.2 & 102.2 & & 9.2 & 8.8 & 88.8 & 95.0 \\
\hline
\end{tabular}

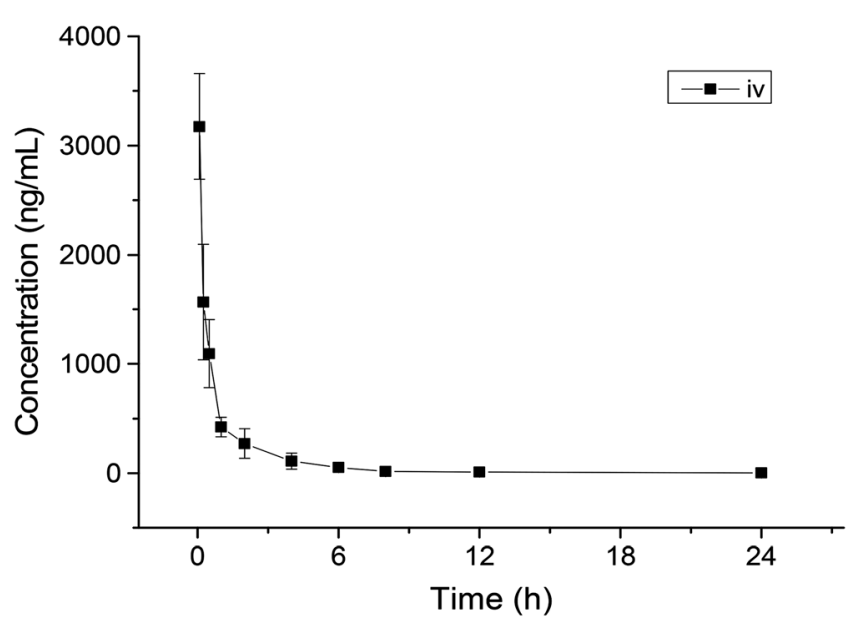

Figure 3. Mean blood concentration of licochalcone A after intravenous administration at the dose of $5 \mathrm{mg} / \mathrm{kg}$ 


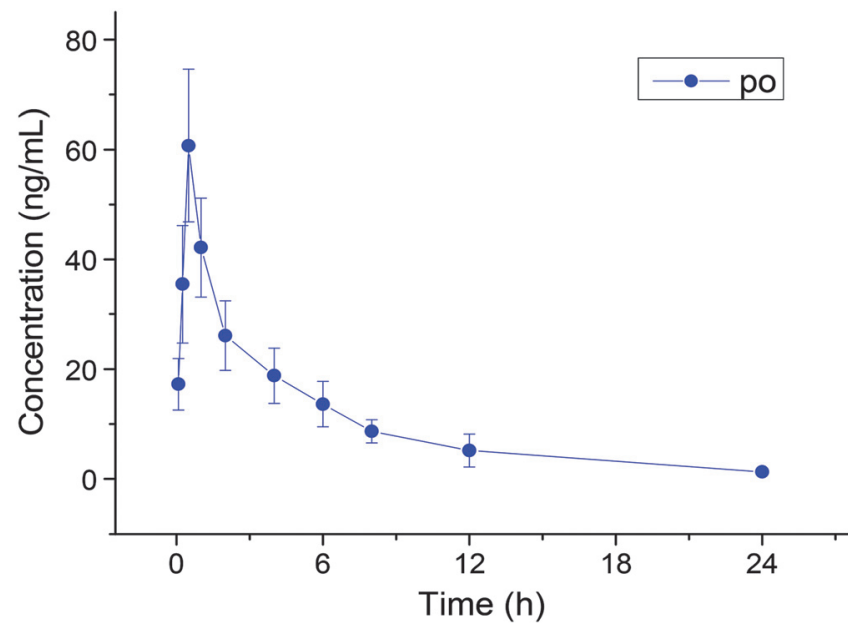

Figure 4. Mean blood concentration of licochalcone A after gavage of $15 \mathrm{mg} / \mathrm{kg}$

Table 2. Main pharmacokinetic parameters of licochalcone A after oral (PO, $15 \mathrm{mg} / \mathrm{kg}$ ) and intravenous (IV, $5 \mathrm{mg} / \mathrm{kg}$ ) administration

\begin{tabular}{lccc}
\hline Parameters & Unit & IV & PO \\
\hline $\mathrm{AUC}_{(0-t)}$ & $\mathrm{ng} / \mathrm{mL}^{*} \mathrm{~h}$ & $2479.9 \pm 326.6$ & $243.3 \pm 44.4$ \\
$\mathrm{AUC}_{(0-\infty)}$ & $\mathrm{ng} / \mathrm{mL}^{*} \mathrm{~h}$ & $2520.1 \pm 352.9$ & $264.9 \pm 59.3$ \\
$\mathrm{MRT}_{(0-t)}$ & $\mathrm{h}$ & $1.9 \pm 0.7$ & $5.4 \pm 0.5$ \\
$\mathrm{MRT}_{(0-\infty)}$ & $\mathrm{h}$ & $2.5 \pm 1.4$ & $7.8 \pm 3.5$ \\
$t_{1 / 2 z}$ & $\mathrm{~h}$ & $6.2 \pm 4.8$ & $6.7 \pm 3.6$ \\
$T_{\max }$ & $\mathrm{h}$ & 0.0833 & 0.5 \\
$\mathrm{CL}_{z / F}$ & $\mathrm{~L} / \mathrm{h} / \mathrm{kg}$ & $2.0 \pm 0.3$ & $58.9 \pm 12.9$ \\
$V_{z / F}$ & $\mathrm{~L} / \mathrm{kg}$ & $17.6 \pm 12.5$ & $536.0 \pm 190.5$ \\
$C_{\max }$ & $\mathrm{ng} / \mathrm{mL}$ & $3173.5 \pm 483.0$ & $60.7 \pm 13.9$ \\
\hline
\end{tabular}

bioavailability after oral administration exhibited a poor absorption and indicated that licochalcone A was easily affected by the first pass effect in the liver (or the intestine).

\section{Conclusion}

We developed and validated a novel and selective UPLC-MS/ MS method to determine the licochalcone A in SD rat plasma. The application of this method for extracting licochalcone A from plasma by a simple protein precipitation procedure was more convenient and faster than traditional and commonly used analytical techniques. We have successfully applied this method to the pharmacokinetic investigation of licochalcone $\mathrm{A}$ in rat after intravenous and intragastric administration. The oral bioavailability of licochalcone $\mathrm{A}$ in mice is $3.3 \%$, exhibiting poor absorption.

Acknowledgement. This work was supported by a grant funded by National natural science foundation of Zhejiang (LS18H27001), Key research and development plan project of Lishui (2016zdyf02) and The Ladder plan of The people's hospital of Lishui (2017TC001).

\section{Reference}

1. Pharmacopoeia, C.o.C. Chinese Pharmacopoeia (Part II) China Chemical Industry Press, Beijing, 2010, vol. 1, p. 247.
2. Fu, Y.; Chen, J.; Li, Y. J.; Zheng, Y. F.; Li, P. Food. Chem. 2013, 141, 1063-1071.

3. Jia, T.; Qiao, J.; Guan, D.; Chen, T. Inflammation 2017, 40, 1894-1902.

4. Tsukiyama, R.; Katsura, H.; Tokuriki, N.; Kobayashi, M. Antimicrob. Agents Chemother. 2002, 46, 1226.

5. Fontes, L. B.; Dos Santos Dias, D.; de Carvalho, L. S.; Mesquita, H. L.; da Silva Reis, L.; Dias, A. T.; Da Silva Filho, A. A.; do Amaral Correa, J. O. J. Pharm. Pharmacol. 2014, 66, 886-894.

6. Nagai, H.; He, J. X.; Tani, T.; Akao, T. J. Pharm. Pharmacol. 2007, 59, 1421-1426.

7. Chen, X.; Liu, Z.; Meng, R.; Shi, C.; Guo, N. J. Ethnopharmacol. 2017, 198, 331-337.

8. Tsai, J. P.; Lee, C. H.; Ying, T. H.; Lin, C. L.; Lin, C. L.; Hsueh, J. T.; Hsieh, Y. H. Oncotarget 2015, 6, 28851-28866.

9. Qiu, C.; Zhang, T.; Zhang, W.; Zhou, L.; Yu, B.; Wang, W.; Yang, Z.; Liu, Z.; Zou, P.; Liang, G. Int. J. Mol. Sci. 2017, 18, 1761.

10. Kang, T. H.; Seo, J. H.; Oh, H.; Yoon, G.; Chae, J. I.; Shim, J. H. J. Cell. Biochem. 2017, 118, 4652-4663.

11. Yang, X.; Jiang, J.; Yang, X.; Han, J.; Zheng, Q. Mol. Med. Rep. 2016, 14, 911-919.

12. Lin, X.; Tian, L.; Wang, L.; Li, W.; Xu, Q.; Xiao, X. Oncol. Lett. 2017, 13, 1695-1701.

13. Rauchensteiner, F.; Matsumura, Y.; Yamamoto, Y.; Yamaji, S.; Tani, T. J. Pharm. Biomed. Anal. 2005, 38, 594-600.

14. Nadelmann, L.; Tjornelund, J.; Christensen, E.; Hansen, S. H. J. Chromatogr. B Biomed. Sci. Appl. 1997, 695, 389-400.

15. Huang, L.; Nikolic, D.; van Breemen, R. B. Anal. Bioanal. Chem. 2017, 409, 6937-6948.

16. Chen, L. G.; Wang, Z.; Wang, S.; Li, T.; Pan, Y.; Lai, X. J. Chromatogr. Sci. 2016, 54, 1336-1340.

17. Ye, W; Chen, R.; Sun, W.; Huang, C.; Lin, X.; Dong, Y.; Wen, C.; Wang, X. J. Chromatogr. B Analyt. Technol. Biomed. Life Sci. 2017, 1060, 144-149.

18. Wang, S.; Wu, H.; Huang, X.; Geng, P.; Wen, C.; Ma, J.; Zhou, Y.; Wang, X. J. Chromatogr. B Analyt. Technol. Biomed. Life Sci. 2015, 990 $118-124$.

19. Zhang, Q.; Wen, C.; Xiang, Z.; Ma, J.; Wang, X. J. Pharm. Biomed. Anal. 2014, 90, 134-138.

20. Wen, C. C.; Lin, C. L.; Cai, X. J.; Ma, J. S.; Wang, X. Q. J. Chromatogr. B Analyt. Technol. Biomed. Life Sci. 2014, 944, 35-38.

21. U.S. Department of Health and Human Services, Guideline on Bioanalytical Method Validation Guidance for Industry, 2011, https://www.fda.gov/downloads/ drugs/guidancecomplianceregulatoryinformation/guidances/ucm070107.pdf.

22. Popowicz, N. D.; O'Halloran, S. J.; Fitzgerald, D.; Lee, Y. C. G.; Joyce, D. A. J. Chromatogr. B Analyt. Technol. Biomed. Life Sci. 2018, 1081-1082, $58-66$.

23. Jiang, Y.; Zhou, H.; Su, K.; Xu, M. Z.; Chen, B. B.; Chen, D. X.; Wen, C. C.; Wu, B.; Luo, X. H.; Wang, X. Q. Lat. Am. J. Pharm. 2016, 35, 2261-2266. 24. Kwon, M. H.; Jeong, J. S.; Ryu, J.; Cho, Y. W.; Kang, H. E. J. Chromatogr. B Analyt. Technol. Biomed. Life Sci. 2017, 1068-1069, 289-296.

25. Ren, K.; Qian, S. Y.; Tu, X. T.; Peng, X. F.; Chen, W. H.; Lin, G. T.; Wang, J. F.; Ma, J. S.; Zhang, Z. A.; Wen, C. C.; Wang, Y. L. Lat. Am. J. Pharm. 2017, 36, 1245-1249.

26. Wu, H.; Yan, Q.; Fan, Z.; Huang, M.; He, J.; Ma, J.; Wang, X. Biomed. Chromatogr. 2018, e4255.

27. Wei, Z.; Ye, L. X.; Jiang, Y. Y.; Zhang, Z. G.; Wang, X. Q. Lat. Am. J. Pharm. 2018, 37, 523-528.

28. Wang, S. H.; Lin, Z. X.; Su, K.; Zhang, J.; Zhang, L. J.; Gao, Z. M.; Wang, Z. Y.; Ma, J. S.; Wang, X. Q. Acta Chromatogr. 2018, 30, 26-30.

29. Geng, P.; Luo, J.; Weng, Z.; Fan, Z.; Zhang, B.; Ma, J.; Wang, X.; Zhang, M. Biomed. Chromatogr. 2018, e4273.

30. Wang, X. Q.; Wang, Q. Q.; Hu, Q. P.; Zhao, Y.; Chen, W. H.; Wen, C. C.; Wu, B. Lat. Am. J. Pharm. 2017, 36, 1403-1407.

31. Zhang, M. L.; Zhang, J.; Wan, L. Y.; Wu, X. L.; Wen, C. C.; Wang, X. Q. Lat. Am. J. Pharm. 2016, 35, 2327-2330.

32. Wang, S.; Wu, H.; Geng, P.; Lin, Y.; Liu, Z.; Zhang, L.; Ma, J.; Zhou, Y.; Wang, X.; Wen, C., Biomed. Chromatogr. 2016, 30, 1145-1149.

33. Wen, C. C.; Wang, S. H.; Huang, X. L.; Liu, Z. Z.; Lin, Y. Y.; Yang, S. P.;

Ma, J. S.; Zhou, Y. F.; Wang, X. Q. Biomed. Chromatogr. 2015, 29, 1805-1810.

34. Wang, X. Q.; Wang, S. H.; Ma, J. S.; Ye, T.; Lu, M.; Fan, M.; Deng, M. J.; Hu, L. F.; Gao, Z. J. Pharm. Biomed. Anal. 2015, 115, 368-374.

35. Wang, S. H.; Ding, T.; Chen, J. M.; Geng, P. W.; Wei, M. H.; Wang, X. Q.; Zhou, Y. F. Lat. Am. J. Pharm. 2015, 34, 253-258.

36. Tian, W. Q.; Cai, J. Z.; Xu, Y. Y.; Luo, X. H.; Zhang, J.; Zhang, Z. X Zhang, Q. W.; Wang, X. Q.; Hu, L. F.; Lin, G. Y. Int. J. Clin. Exp. Med. 2015, $8,15164-15172$.

37. Ma, J. S.; Wang, S. H.; Huang, X. L.; Geng, P. W.; Wen, C. C.; Zhou, Y. F.; Yu, L. S.; Wang, X. Q. J. Pharm. Biomed. Anal. 2015, 111, 131-137. 